\title{
LABORTERAPIA NA PROMOÇÃO DA SAÚDE NO TRABALHO SOB A PERSPECTIVA DA SOCIONOMIA
}

\section{LABORTHERAPHY FOR THE PROMOTION OF OCCUPATIONAL HEALTH FROM THE SOCIONOMY PERSPECTIVE}

\author{
Maria Luiza Gava Schmidt \\ Autora para correspondência: Maria Luiza Gava Schmidt - Ischmidt@assis.unesp.br \\ Psicóloga pela Universidade Estadual Paulista Júlio de Mesquita Filho. Mestre em Psicologia pela \\ Universidade Estadual Paulista Júlio de Mesquita Filho. Doutor em Saúde Coletiva pela Universidade \\ Estadual de Campinas. Pós-Doutora em Saúde Pública pela FSP/USP
}

R E S U M O

\begin{abstract}
Introdução: O termo Laborterapia, citado pelo médico Jacob Levy Moreno, precursor da Socionomia, é a ciência que estuda as leis sociais e que está estruturada em três ramos (Sociometria, Psicodrama/Sociodrama, Sociatria) tendo sido criada por ele nas primeiras décadas do século XX. Objetivo: Este texto visa: Resgatar o significado do conceito de Laborterapia; Apresentar a experiência de Moreno como médico do trabalho, em especial um exemplo de sua atuação em uma lavanderia e; Ressaltar a importância da utilização de métodos socionômicos para propiciar o espaço de expressão e mobilização subjetiva dos trabalhadores. Metodologia: Em suas ações, Moreno utilizou entrevistas individuais (para verificar as razões das escolhas ou rejeições) antes e após a reorganização do grupo e o sociograma, um procedimento embasado na sociometria que permite visualizar os conflitos, compreendê-los e intervir na vincularidade grupal, de modo a resolver conflitos de relacionamento e melhorar aspectos da organização do trabalho. Resultados: Para Moreno, o resultado foi promissor, pois houve uma reorganização do grupo, sendo que os atritos interpessoais diminuíram acentuadamente e a produção aumentou para um tempo de trabalho reduzido. Suas experiências revelaram que a sociometria como forma de propiciar a coesão grupal é uma abordagem promissora na promoção da saúde no trabalho. Considerações Finais: Nossas experiências no campo da saúde no trabalho, mediante a utilização de métodos socionômicos preconizados por Moreno, revelaram que a abordagem socionômica é relevante, pois além de propiciar o espaço de expressão e mobilização subjetiva dos trabalhadores, confirmou a função terapêutica desta metodologia.
\end{abstract}

Palavras Chave: Psicodrama, Medicina do Trabalho, Promoção da Saúde 
Introduction: The term Labortheraphy, mentioned by doctor Jacob Levy Moreno, pioneer of Socionomy, is the science that studies the social laws and is structured in three branches (Sociometry, Psychodrama/Sociodrama, Sociatry) having been created by him in the first decades of the 20th century. Objective: This article aims to: Redeem the meaning of the concept of Labortheraphy; Present Moreno's experience as an occupational physician, especially an example of his practice in a laundry and; Emphasize the importance of using socionomic methods to provide the space for expression and subjective mobilization of workers. Methodology: In his actions, Moreno used individual interviews (to verify the reasons of the choices or rejections) before and after the group reorganization and the sociogram, a procedure based on sociometry that allows the diagnosis and comprehension of conflicts and the intervention in group methodologies aiming to resolve relationship conflicts, and improve aspects of work organization. Results: According to Moreno, the result was promising because the group was rearranged, and the interpersonal conflicts were remarkably reduced, consequently increasing the production for a reduced working time. Those experiences revealed that sociometry as a way to promote group cohesion is a promising approach for the promotion of occupational health. Final Considerations: Our experiences in the occupational health field, by using socionomic methods recommended by Moreno, revealed that the socionomic approach is relevant, once, in addition to providing the space for expression and subjective mobilization of workers, it confirmed the therapeutic function of that methodology.

Keywords: Psychodrama, Occupational Medicine, Health Promotion 


\section{INTRODUÇÃO}

O termo Laborterapia, foi citado pelo médico Jacob Levy Moreno, precursor da Socionomia, ciência que estuda as leis sociais e que está estruturada em três ramos (Sociometria, Psicodrama/Sociodrama, Sociatria) criada por ele nas primeiras décadas do século XX. Mediante um vasto acervo de conceitos científicos e técnicas, esta abordagem alicerça a leitura das interações grupais e a formulação das hipóteses bem definidas acerca de fatos sociais e da realidade grupal e auxiliam a práxis dos profissionais e a pesquisa, nas diversas áreas das ciências humanas, sociais e da saúde'.

A trajetória intelectual de Moreno, foi significativa para inovar as concepções sobre o ser humano em diferentes áreas do conhecimento, sobretudo, no âmbito das Ciências Sociais e da Psiquiatria ${ }^{2-6}$.

Estimulado pela filosofia existencialista, que predominava na Arte e na Filosofia da época, projetou no ramo da psiquiatria, a visão de mundo com princípios voltados à compreensão das necessidades singulares de cada pessoa.

Sob essas influências, rompeu contra as classificações sistemáticas na área de saúde mental, escolhendo atuar como médico de família e do trabalho, adotando uma visão psicossomática na área de Saúde Pública. Costumava visitar os doentes e atendê-los em casa, de graça, exercendo uma medicina incomum para época ${ }^{7}$.

Como médico do trabalho, atuou numa indústria têxtil em Bad Voslau, pequena cidade ao sul de Viena ${ }^{7}$. Apesar de ter deixado poucos escritos de sua atuação nesta área, mencionou como ter sido uma experiência valiosa ${ }^{4}$. Em seus estudos deixou alguns escritos, como o fato de ter observado uma maior frequência de acidentes do trabalho entre trabalhadores isolados dos que trabalhavam em equipe muito unida ${ }^{4}$.
E em uma de suas obras, registrou sua atuação numa lavanderia mediante a utilização da sociometria, um ramo da Socionomia que se ocupa do estudo das características psicossociais da população, das síndromes características de um grupo, bem como busca encontrar métodos com os quais se possam tratar os grupos e indivíduos eficazmentes ${ }^{8.4}$.

Nesta experiência com 10 trabalhadoras, das quais sete operadoras exerciam as funções de recolher e dobrar as roupas, uma contramestre e duas encarregadas de alimentar uma máquina. Segundo ele, o estudo foi realizado devido ao fato delas se rejeitarem mutuamente e isto, ocasionar conflitos entre elas perturbando o desenvolvimento do trabalho, além de ocasionar uma crise emocional que atingia $\circ$ grupo 4 .

Como técnicas, neste contexto, ele utilizou entrevistas individuais (para verificar as razões das escolhas ou rejeições) antes e após a reorganização do grupo e o sociograma, um procedimento embasado na sociometria, que permite visualizar os conflitos, compreendê-los e intervir na vincularidade grupal ${ }^{9}$.

Na sua opinião, esta foi certamente a primeira vez que as trabalhadoras foram submetidas à laborterapia e o resultado por ele descrito, mostrou que houve uma reorganização do grupo, sendo que os atritos interpessoais diminuíram acentuadamente e a produção aumentou, para um tempo de trabalho reduzido ${ }^{4}$.

Ao final, descreveu que comparou os resultados do sociograma com o comportamento real e que no caso de persistência de uma das integrantes do grupo em rejeitar a colega de trabalho ele a encaminhou para treinamento de papéis e diagnóstico mediante o psicodrama e assim, ela vivenciou um conjunto de situações de trabalho o que contribuiu para sua (re) educação no engajamento no grupo de trabalho.

Destarte, com base em suas experiências, especialmente com este grupo de trabalhadoras, ele fez referências ao conceito de Terapia pelo Trabalho (Laborterapia), que na sua opinião, segue os princípios assim definidos ${ }^{4}$ : 
1. O trabalho é executado no local de trabalho original (in situ) nas fábricas, escritórios, empresas comerciais. Os lugares do trabalho e da terapia são os mesmos. A terapia é ou se torna uma parte do processo de trabalho.

2. Os membros do grupo são, ao mesmo tempo, trabalhadores e pacientes.

3. Serão pagos e segurados, de acordo com a legislação do país.

4. A terapia pode dirigir-se a problemas administrativos, técnicos e interpessoais.

Moreno considera que o entendimento da realidade se dá no contato com a própria realidade e, assim sendo, propõe que as intervenções metodológicas devem ocorrer in situ, ou seja, quando as questões envolvem o local de trabalho a intervenção deve acontecer no contexto de trabalho com a participação dos trabalhadores.

\section{CONSIDERAÇÕES FINAIS}

Ao nosso ver, enquanto atuações como médico do trabalho, preconizou a importância do diagnóstico para entendimento das questões psicossociais que afetam $\circ$ ambiente de trabalho, mostrou também a importância da participação dos trabalhadores no levantamento dos dados, bem como no processo interventivo. $E$, sobretudo, nos idos do início do século $X X$, seus ensinamentos nesta área já revelaram que é preciso intervir na organização do trabalho, a grande vilã do adoecimento mental dos trabalhadores $^{10-13}$.

Como adepto da concepção de que o indivíduo adoece e se cura no social e, considerando que - local de trabalho é um espaço social, Moreno atuando como médico do trabalho, apontou que o ambiente laboral pode ser fonte de adoecimento mas também de promoção da saúde. Ademais, evidenciou que a coesão grupal é proporcionada pela interrelação afetiva dos indivíduos no grupo, fato este constatado no trabalho contemporâneo por Seligmann- Silva (2003) ao afirmar que "a coesão, resultante da construção coletiva de laços de confiança e solidariedade, possui grande significado na proteção à saúde mental" "1 1 .

O mundo do trabalho, na forma como está organizado, tem impedido um relacionamento sadio entre os trabalhadores, sobretudo em decorrência da competitividade exacerbada, pressões, assédio, medo, entre outras vivências do cotidiano de trabalho que colocam a saúde mental dos trabalhadores em risco $^{14,15}$.

Nossas experiências no campo da saúde no trabalho, mediante a utilização de métodos socionômicos preconizados por Moreno, revelaram que a abordagem socionômica é relevante, pois além de propiciar o espaço de expressão e mobilização subjetiva dos trabalhadores, demonstrou também como uma função terapêutica na medida em que favorece o desenvolvimento da criatividade e da espontaneidade bloqueadas pela organização do trabalho ${ }^{12,13,16}$.

\section{REFERÊNCIAS}

1. Ramos MEC. O agir interventivo e a pesquisa-ação. In: Marra M. M; Fleury H. J. (org) Grupos- intervenção socioeducativa e método sociodramático. São Paulo: Ágora; 2008. P. $45-55$

2. Schmidt MLG. Algumas reflexões acerca da construção e contribuições da teoria socionômica. Psicologia para América Latina. 2007;1 1

3. Moreno JLD. Imprompuman. J.L Moreno e as origens do psicodrama, da cultura do encontro e das redes sociais[Datner YB, trad]. 1 ed. São Paulo: FEBRAP; 2016

4. Moreno JL. Psicoterapia de grupo e psicodrama: introdução à teoria e à prática [Gomes JCV, trad]. $3^{\mathrm{a}}$ ed. Campinas: Livro Pleno; 1999

5. Moreno JL. Fundamentos do psicodrama [Neto MSM, trad]. São Paulo: Summus Editorial Ltda; 1983

6. Moreno JL. Psicodrama [Cabral A, trad]. 2 ed. São Paulo: Cultrix; 1978

7. Ramalho CMRR. Aproximações entre Moreno e Jung. 
8. Cukier R. Palavras de Jacob Levy Moreno: vocabulário de citações de psicodrama, da psicoterapia de grupo, do sociodrama e da sociometria. São Paulo: Ágora; 2002

9. Menegazzo $C M$, Zuretti $M M$, Tomasini MA. Dicionário de psicodrama. São Paulo: Ágora; 1995

10. Dejours C. A loucura do trabalho. Estudo da psicopatologia do trabalho. $5^{a}$ ed. São Paulo: Oboré; 1992

11. Seligmann-Silva E. Psicopatologia e saúde mental no trabalho. In: Mendes, R. Patologia do trabalho. São Paulo: Atheneu; 2003. P.1141-1182

12. Schmidt MLG. Uma Leitura Sociodramática Sobre o Processo Saúde - Doença no Trabalho na Contemporaneidade. Psicologia para América Latina. 2010;19

13. Schmidt MLG. Saúde e doença no trabalho: uma perspectiva sociodramática. São Paulo: Casa do Psicólogo; 2010

14. Sampaio JR. Qualidade de vida, saúde mental e psicologia social: estudos contemporâneos. São Paulo: Casa do Psicólogo; 1999

15. Jaques MC, Codo W. Saúde mental e trabalho leituras. $4^{\mathrm{a}} \mathrm{ed}$. Petrópolis: Editora Vozes; 2010

16. Lucca SR, Schmidt MLG. Psicodrama: uma abordagem metodológica qualitativa para o estudo da saúde do trabalhador. Psicol. Am. Lat. 2004;2 